\title{
LAS RUTAS DE LUIS
} ASTEY

\author{
Gabriel Astey*
}

\section{Luis Astey tenía la idea de que los} recordatorios fúnebres eran, sobre todo, un engorro. Admitía, con cierta condescendencia mordaz, que se dieran dentro del breve grupo de los parientes y amigos del recordado, y llamo mordaz a esta aquiescencia suya porque el hecho mismo del recuerdo convertido en discurso le parecía tanto una vanidad de parte de los aún vivos, como una especie de ostentación post-mortem de la propia persona por parte del difunto; es decir, una vanidad aún más absurda. Aunque esencialmente bíblico en estos pareceres, no se vaya a creer que los defendía a ultranza; uno de sus rasgos personales más gratos era su desapego hacia cualquier clase de idiosincrasia militante, ortodoxa o heterodoxa. Por ello, creo que textos como éste y los que se podrán leer enseguida le habrían provocado una respuesta de esencial y espontánea gratitud. Contemos, pues, con un hipotético beneplácito suyo al respecto.

En lo tocante a mi recuerdo me propongo ofrecer aquí a los lectores, de modo más o menos biográfico y anecdótico, una serie de aspectos de lo que, sin querer ser pedante, yo llamaría su personalidad intelectual. A mi modo de ver las cosas, mi padre fue esencialmente un lector, más precisamente, un lector feliz. Mis primeros recuerdos en este sentido me lo muestran sentado y sereno durante horas ante sus libros, con un gesto de curiosidad e inmersión aventurera en la lectura que formaba la contraparte exacta de su variadísima bibliote-

* Estudiante de la Maestría en Teoría Literaria, UAM. 
GABRIEL ASTEY

ca: "Soy un vagabundo desde el punto de vista intelectual", dijo alguna vez a un periodista que le preguntaba si su devoción por la literatura medieval era exclusiva. Me atrevo a decir que todas su incursiones en el campo de la investigación fueron sólo ramificaciones sistematizadas de ese insaciable interés por la lectura, $y$, sobre todo, por la lectura literaria. Ahora bien, ¿cuáles fueron los caminos que ese apetito siguió?

Oriundo de Guadalajara y huérfano por partida doble desde temprana edad, vivía mi papá con unas tías abuelas de un puritanismo insoportable que, afortunadamente, tenían una casona lilena de cuartos semiclausurados en los que él podía esconderse de ellas para jugar. La única tía, digamos decorosa, era una maestra de escuela primaria que quería mucho a Luis y le regaló en algún cumpleaños El tesoro de la juventud, con el obsequio adicional de un permiso para recluirse a leer en aquellos cuartos vacíos. Esa fue su lectura iniciática, por así decirlo, pues, según él mismo me contó, en esos libros halló el, no por trillado menos significativo, placer de escapar de la aburridísima realidad cotidiana.

A partir de entonces las lecturas crecieron: primero, con la herencia de la biblioteca de la tía decorosa (básicamente libros ñoños del ro166 manticismo tardío hispánico y del realismo y el modernismo más convencionales), que exploró y pronto hizo a un lado (a la biblioteca, se entiende, no a la tía, aunque también le tocó explorar a las tías en los momentos en que fueron muriendo, pues era el hombre mayor de la casa y en él recaía la función de comprobar, antes que el médico, la defunción de las susodichas, y digo esto porque era una extravagante atribución cuasi oficial que él recordaba con muy buen humor). Desechó, pues, esos libros, con la salvedad del peregrino caso de una edición de 1899 de Les fleurs du mal, cuyo hallazgo entre tanta medianía celebró en un arranque adolescente mandándola encuadernar en piel. En segundo lugar, el interés creció con el descubrimiento de los clásicos grecolatinos en la biblioteca pública de Guadalajara, descubrimiento que se convirtió a la larga en una frecuentación asidua y exhaustiva de la cultura clásica. Y, finalmente, ya en su primera juventud, su pasión tomó buen rumbo gracias a una serie de circunstancias que impidie- 
ron su profesionalización en el campo de los estudios literarios y le dejaron un espacio de autodidactismo que él siempre apreció.

Vino entonces el asunto de estudiar derecho, por la sencilla razón de parecerle menos insufrible y más avecinado a las letras que la ingeniería o la medicina, y en el transcurso de la carrera encontró que el derecho en sí no era nada desdeñable, pero también cayó en cuenta de que la praxis jurídica era completamente imposible para su temperamento solitario, por lo que, obtenido el título, vino a la ciudad de México y se inscribió en letras clásicas en la Facultad de filosofia y letras. De dicha licenciatura solamente cursó un año, pues el temperamento solitario le hizo aceptar con mucho gusto el ofrecimiento de dar clases en la preparatoria del ITESM de Monterrey y hacer el resto de los estudios en la Universidad de Nuevo León, que nunca terminó por no existir las letras clásicas allá hacia 1946, habiéndolos ido a buscar con la ingenua confianza de quien se guía en estas cosas de oídas.

Valga hacer aquí un excurso anecdótico sobre el mentado temperamento solitario, la enseñanza en el bachillerato y el seguimiento de sus estudios grecolatinos: respecto a lo primero, recuerdo que cuando alguna vez le pregunté qué hubiera querido ser de haber vivido en el medievo, en vez de oír la respuesta que esperaba, algo a medio camino entre profesor de la Sorbona y abad cisterciense, me dijo "monje del desierto, y que se me dejara en paz"; en cuanto a lo segundo, sus pininos como profesor los hizo en una secundaria tapatía para niñas, en la que causó escándalo cuando pidió como lectura imprescindible del curso La Celestina, libro del que, tal vez por las propias alumnas, las monjas a su cargo se enteraron que versaba sobre una "puta vieja" y otros tantos transgresores de la moral decimonónica. Respecto a lo último, la inexistencia de las letras clásicas no impidió su inmersión en los autores griegos y latinos: el latín lo había aprendido bastante bien durante el bachillerato y se hizo del griego, en parte por la enseñanza de un sacerdote regiomontano cuyo nombre ya no recuerdo, en parte por la del maestro Antonio Gómez Robledo. 
A partir de aquí, el desarrollo de su erudición durante casi 30 años de estancia en Monterrey se debió a varios factores. Su longeva y constantemente mejorada cátedra de Historia de la cultura (así como otras tantas de diversos asuntos literarios), su capacidad de hacerse de infinidad de libros y revistas especializadas en su cargo de director de la biblioteca del ITESM, y dos visitas académicas al extranjero de las que, como solía poner en su curriculum, no conservó ningún comprobante de estudios.

En 1948 fue a París con la esperanza de aprender hebreo, pero descubrió que no había forma de estudiarlo en la Sorbona, tal vez a causa de los cercanos desastres de la guerra. Optó, pues, por dedicarse al acadio y al drama latino medieval; en el primer caso, el interés por la literatura mesopotámica le vino de la cercanía de algunos textos religiosos con la Biblia y su posible función de fuente para ciertos mitos veterotestamentarios; en el segundo, porque lo entusiasmó conocer al profesor Gustav Cohen, judío converso y profesor de literatura latina medieval que, en su fervor religioso, escenificaba los breves dramas litúrgicos de la Edad media en los pórticos de las iglesias parisinas. La pasión de mi padre por tales dramas, que lo llevó a componer, editar y traducir al castellano un corpus representativo de los mismos ( $\sin$ duda el más complejo y erudito de sus libros), tenía raíces afines a la pasión de Cohen. Desde pequeño, Luis, agnóstico manso y antidogmático enfurruñado, encontró que en el catolicismo la liturgia era fascinante, y fascinante, como él mismo me dijo, en el sentido de la fascinación ante el mysterium de que hablan los fenomenólogos de la religión como una de las experiencias de estremecimiento interior, de esas que, en el interior de un credo específico, nutren y sustentan la fe. En el caso de mi padre la experiencia quedaba sólo en el estremecimiento, pero eso bastó para aficionarlo al fenómeno litúrgico. Cabe agregar que él mismo decía tener con la literatura un vínculo pasional de indole más o menos religioso y, para explicarlo, se apoyaba en Kierkegaard y su idea de la experiencia estética como una antesala de la experiencia divina, si bien siempre se mostró escéptico en lo tocante a Dios; le gustaba la faceta furibunda de Jesús (aquello de traer la 
espada y no la paz) y los arranques de furia sagrada mosaica. En fin, también los monjes del desierto eran unos tercos, y del más alto grado de terquedad.

De su estancia en Harvard en 1959 no hay frutos materiales (como hay las traducciones de los mentados dramas, de las obras de Hrotstvitha de Gandersheim y de Hildegard von Bingen, del Enuma elish acadio, en el caso de la visita a Francia), no obstante lo interesantes que hubieran podido ser: estudió allí, bajo la tutoría de Werner Jaeger, los fragmentos de Eurípides, pero al parecer sin intención alguna de hacer algo publicable con ellos, simplemente por afición. En cuanto a Jaeger mismo, ante mi pregunta por cómo era, sólo dijo: "un señor profesor como cualquier otro, muy correcto, que me recibía en su casa", nada más.

Éstas son, creo, las vicisitudes señeras de su biografia intelectual, al menos hasta su establecimiento aquí en la ciudad de México, a partir de los setenta. En esta última época, que me tocó vivir con él, fue en la que comenzó a actualizar y concluir para la prensa sus investigaciones más importantes, pero yo siempre lo vi como un lector feliz y no como un investigador de SNI sumergido en el trabajo académico. Si entrara yo en detalles de su vida intelectual en el ITAM, El Colegio de México o la Facultad de filosofía y letras, compondría un anecdotario que pasaría del recordatorio engorroso al engorro absoluto. Además, quienes con él convivieron conservan una imagen que no puede ni necesita actualizarse en este discurso. Valga, pues, solamente, traer a la memoria un último detalle: solía dedicarme sus libros con una ironía y sinceridad que tengo muy presentes, con frase como "para Gabriel, esperando que esto no le sea un estorbo". Pero hay una dedicatoria que ahora quiero traer a colación porque se me ha vuelto una muletilla interior de gratitud hacia las personas queridas: "para Gabriel, con mi agradecimiento porque existe". Sea este texto una especie de constancia de mi gratitud por su colaboración en mi existencia y, por supuesto, por la existencia de él. 